\title{
Computational model explaining two types of bursting found in inspiratory pacemakers.
}

\author{
Natalia Toporikova ${ }^{1,2^{*}}$, Robert Butera ${ }^{1,2}$ \\ From Nineteenth Annual Computational Neuroscience Meeting: CNS*2010 \\ San Antonio, TX, USA. 24-30 July 2010
}

The respiratory rhythm is generated within the network of inspiratory neurons in the pre-Bötzinger complex (pBC) and persists under highly variable neuronal input. The mechanism of $\mathrm{pBC}$ rhythm generation at the level of the network is an active area of debate and inquiry. A fraction of these inspiratory $\mathrm{pBC}$ neurons generate a stable bursting rhythm even when pharmacologically isolated from the network and likely contribute to the rhythm. Experiments indicate that the intrinsic bursting mechanism of these pacemaker neurons depends on either persistent sodium current or changes in intracellular $\mathrm{Ca}^{2+}$. Motivated by experimental evidence obtained from these subpopulations of bursting neurons, we developed a two-compartment mathematical model of a $\mathrm{pBC}$ pacemaker neuron with two independent bursting mechanisms. The model explains a number of contradictory experimental results and is able to generate a robust bursting rhythm over a large range of parameters, with a frequency adjusted by neuromodulators.

For the somatic compartment of our model, we used a previously developed model of $\mathrm{pBC}$ pacemaker neurons [1]. In this model, action potentials are generated by a fast sodium current $\left(I_{\mathrm{Na}}\right)$ and a delayed rectifier potassium current $\left(I_{K}\right)$, and the burst is terminated by slow inactivation of a persistent sodium current $\left(I_{N a P}\right)$. The bursting in the dendritic compartment of our model follows the $\mathrm{Ca}^{2+}$ oscillations arising from periodic $\mathrm{Ca}^{2+}$ release from intracellular stores. Briefly, the activation of a $\mathrm{G}_{\mathrm{q}}$-protein cascade leads to an increase in the concentration of $I P_{3}$, which binds to its receptor on the surface of the endoplasmic reticulum and initiates $\mathrm{Ca}^{2+}$ influx into the cytosol. A calcium-activated nonspecific cation current $\left(I_{C a N}\right)$ then depolarizes the cell membrane in response to the increase in intracellular $\mathrm{Ca}^{2+}$ concentration. This depolarizing potential spreads to the soma and activates action potential-generating currents $\left(I_{N a}\right.$ and $\left.I_{K}\right)$, thus initiating the burst. Finally, the action potential propagates to the dendrite, producing a dendritic burst of smaller amplitude.

The model predicts that in synaptically isolated cells, the bursting mechanism depends on neuromodulators, endogenously released within the $\mathrm{pBC}$. The neuromodulatory tone can bias the neuron to a somatic $\left(I_{N a P}\right)$ or dendritic $\left(\mathrm{Ca}^{2+}\right.$ and $\left.I_{\mathrm{CaN}}\right)$ mode of bursting, or a hybrid of the two. In the dendritic mode, the period of bursting is largely modulated by the $I P_{3}$ concentration, whereas in the somatic mode the burst duration is modulated by the persistent sodium current. This model displays changes in burst duration and period that are consistent with experimentally published pharmacological manipulations, such as the application of ion channel blockers (FFA and Riluzole) as well as neuromodulatory manipulations.

\section{Author details}

${ }^{1}$ Laboratory for Neuroengineering, Georgia Institute of Technology, Atlanta, GA 30332, USA. ${ }^{2}$ School of Electrical and Computer Engineering, Georgia Institute of Technology, Atlanta, GA 30332, USA.

Published: 20 July 2010

doi:10.1186/1471-2202-11-S1-O2

Cite this article as: Toporikova and Butera: Computational model explaining two types of bursting found in inspiratory pacemakers.. BMC Neuroscience 2010 11(Suppl 1):O2. 